\title{
Modeling and Forecasting Mortality in Sri Lanka Wasana Aberathna ${ }^{1}$, Lakshman Alles ${ }^{2}$, W. N.Wickremasinghe ${ }^{1 *}$ and Isuru Hewapathirana ${ }^{1}$ \\ ${ }^{1}$ Department of Statistics, University of Colombo, Colombo 3, Sri Lanka \\ ${ }^{2}$ School of Economics and Finance, Curtin University, Australia \\ *Corresponding Author:wnw@stat.cmb.ac.lk
}

Received: 28, January 2014 / Revised: 15, August 2014 / Accepted: 27, August 2014

(C) IAppStat-SL 2013

\begin{abstract}
The purpose of this study is to develop sex-specific mortality estimation models using historical mortality data for Sri Lanka, based on the statistical time series techniques attributed to Lee and Carter (1992). Historical mortality data was analyzed in the light of significant historical episodes. Several alternative univariate time series models were examined for modeling males and females, as well as a bivariate vector autoregressive (VAR) model. The VAR model when fitted to the first differenced series performed better than the univariate models and hence used for forecasting purposes. From the estimated VAR model, mortality forecasts were generated for the period up to 2030 and life tables were generated for the selected periods of 2006-2008.
\end{abstract}

Keywords: Ageing, Mortality forecasting, life tables, Sri Lanka

\section{Introduction}

\subsection{Background}

The life expectancy at birth in Sri Lanka as at 2007 is 70.3 years for males and 77.9 years for females (Central Bank of Sri Lanka, 2009) and this has been increasing over time. As a result of increasing life expectancy and decreasing mortality, the population in Sri Lanka and the world in general, is ageing. An ageing population is commonly defined as one with an increasing proportion of the population in the elderly groups. The speed of ageing is relatively higher in Asia (Borsch, 2009) and in fact, Sri Lanka has the fastest-ageing population in South Asia (Abeykoon, 1996; Sri Lanka Aging Survey, 2006). Elderly Sri Lankans (aged $\geq 60$ years) constituted 9.1 percent of the population in the 2001 
census, an increase of 2.5 percentage points from the previous census of 1981 (Department of Census and Statistics of Sri Lanka). The latest estimates for 2006 put this figure at 9.4 percent (Ostbye et. al., 2010).

An ageing population results in an increase in the number of pensioners and retirees. The traditional custom in Sri Lanka is for the elderly to be cared for by their children and to be supported financially by them, at least partially. Due to factors such as increased migration from rural areas to urban areas, and migration overseas for employment, the family support base for the elderly in Sri Lanka is increasingly diminishing (De Silva, 2005). Gamaniratne (2007) reports that the old age dependency ratio ${ }^{1}$ which stood at $10 \%$ in 2000 is projected to increase to $18 \%$ in 2020 and $27 \%$ in 2040 . These trends highlight the need for the elderly to be increasingly self-supportive in the future. Gamaniratne (2007) further reports that Sri Lanka's social security system covers only $25 \%$ of the working age population. The expected growth in the elderly population and the need to extend the coverage of social security to a larger proportion of the population underscore the need to strengthen social security programs in the future. In such a context the government of Sri Lanka would need to deal with the issues of providing retirement benefits to an increasing population of retirees, the fiscal affordability of doing so, and optimizing the design of pension systems for achieving these policy objectives.

There are three components that affect population demographics; fertility, mortality and migration. Sri Lanka, like many other developing countries in the Asia Pacific region, has entered the third stage of demographic transition, the phase of declining fertility and mortality (De Silva, 1994). Fertility control policies, increasing education of reproductive practices, increases in the marital age of females with education have contributed to the decline in fertility. Effective application of DDT in national efforts to eradicate malaria, improvements in the health care system, improvements in agricultural production and subsidized distribution of food items and the expansion of free educational services, all have directly or indirectly contributed to mortality decline in Sri Lanka. The 30-year war in Sri Lanka also took a heavy toll on the lives of younger age groups. With the end of the war in 2009, it is expected that the demographic patterns will change in the future. The population size in Sri Lanka may also be impacted as migratory patterns change after the end of the war.

${ }^{1}$ old age dependency ratio is the ratio of people aged 60 and over to those between aged 15 to 64 
The three components affecting population demographics, fertility, mortality, and migration, need to be studied and analyzed for formulating policies and mechanisms for enhancing the financial security of retirees in Sri Lanka. Mortality projections are an essential pre-requisite for any exercise relating to government pension policy formulation and pension modeling.

Mortality projections are also important for public and private sector financial institutions such as insurance companies, pension plans and provident funds that offer long term financial products such as retirement pensions, annuities and life and health insurance policies. The financial viability of these institutions are crucially dependent on properly managing their balance sheet assets and liabilities, and the risks related to those assets and liabilities. The risk of mortality changes has a significant impact in assessing and modeling the liabilities relating to such long term financial products. Significant improvements in longevity observed in the recent past indicate that modeling and projecting longevity requires a stochastic modeling approach, rather than the traditionally used deterministic approaches.

Population projections for Sri Lanka have been compiled by De Siva (2007). These projections are based on a demographic cohort component approach, where age specific five year survivorship ratios and population data for mid-year five year age groups are utilized to project future population in five year age brackets.

\subsection{Need for Modeling Mortality in Sri Lanka}

As far as the authors are aware, no studies have so far utilized such statistical modeling techniques based on historical data for projecting mortality in Sri Lanka. The Lee-Carter (1992) statistical modeling technique differs from the approach of forecasting age-specific rates independently. It exploits the high degree of inter-temporal correlation structure across the ages, by making all death rates functions of the same time varying parameter.

The objective in this paper is to apply statistical modeling techniques similar to those applied by Lee and Carter (1992) to model mortality in Sri Lanka, and utilize the models to project future sex-specific and age-specific mortality in Sri Lanka, and to provide probabilistic confidence regions for the projections. Life tables are also constructed and interpreted using 2006, 2007 and 2008 data. To achieve this objective, first the historical information on the population size and mortality rates is gathered and then the Lee-Carter (1992) modeling technique is applied to Sri Lankan data, in order to develop an appropriate time series 
mortality estimation model. The efficacy of the model is evaluated with appropriate diagnostics.

Thus, the results of this study will fill a serious information deficiency currently faced by financial institutions and government policy makers in Sri Lanka.

\section{Methodology}

\subsection{Data Collection}

In this study, the data collection process was the most difficult part. To develop life tables and mortality models, age-specific mortality rates must be available. Unfortunately the data available (reported) in Sri Lanka was incomplete, and the data gaps needed to be filled. This study is based on data collected from several sources for the period 1950 - 2010. This consists of age-specific and sex-specific midyear population sizes for 1950 - 2010 collected from statistical abstracts published by the Department of Census and Statistics, and age-specific, sexspecific number of deaths registered from 1950 to 2008 at the Registrar General's office.

In 1990, the number of deaths was not reported. Therefore it was estimated as the average of the number of deaths in 1989 and 1991. In some cases population sizes and number of deaths available in various age groups did not correspond to our age groups. Therefore, the data needed for our age groups had to be extrapolated from available records. To build life tables, 2006, 2007 and 2008 sex-specific, age specific death rates were used. These were calculated from death rates using age-specific midyear population sizes and age-specific number of deaths. As the death rates for the age groups $0-1$ and $1-4$ were not consistently available they were calculated as follows:

Number of deaths in 0 - 1 age group was calculated for each year using number of deaths registered in 3-month intervals (which was available) below 1 year. Midyear population size was available for the $0-4$ age group, and $0-1$ age group as a proportion of $0-4$ age group was obtained from the census of population and housing -2001 . Therefore, the death rate for $0-1$ age group was estimated as the ratio of number of deaths in that interval to the midyear population size (calculated as a proportion) for that interval. Number of deaths in $1-4$ age group was calculated as the total number of deaths reported for ages $1,2,3$, and 4 . Then the midyear population size for $1-4$ age group was obtained as a proportion of the midyear population size for $0-4$ interval from the population and housing census -2001 . Then, the death rates for $1-4$ were estimated using the corresponding ratio as before. 


\subsection{The Lee-Carter (LC) Approach}

Lee-Carter model (Lee and Carter, 1992) has been considered a gold standard for mortality forecasting in recent times (Lee and Miller, 2001; Li et. al., 2004; Li and Lee, 2005; Li and Chan, 2007; Li et. al., 2011). The original work by Lee and Carter (1992) combines a rich yet parsimonious demographic model with statistical time series methods to forecast age-specific mortality in USA for the period 1990 to 2065. They have used historical age-specific death rates for the entire US population for the period 1933-1987 for the purpose of model fitting. This method is extrapolative and makes no effort to incorporate knowledge about medical, behavioral, or social influences on mortality change. Its virtues are that it combines a rich yet parsimonious demographic model with statistical time series methods. Annual age-specific death rates are used for this method.

Let $m(x, t)$ denote the central death rate for age $\mathrm{x}$ in year $\mathrm{t}$.

The original Lee-Carter approach goes on to forecast $m(x, t)$ for given $t$, using the model

$$
\log _{e}[m(x, t)]=a_{x}+b_{x} k_{t}+\varepsilon(x, t)
$$

where $\varepsilon(x, t)$ is a random error component. According to Lee and Carter (1992), the model parameters $a_{x}, b_{x}$, and $k_{t}$ are estimated using a rank-1 approximation of the singular value decomposition (SVD) of the matrix $\left\{\log _{e}[m(x, t)]-a_{x}\right\}$ as discussed by Good (1969); and Johnson and Wichern ( 2002), and the final 'adjusted' estimate of $k_{t}$ (as explained by Lee and Carter, 1992) is then modeled using a standard time series approach. In particular, the LC approach consists of six key steps: Namely,

1. Estimating model parameters using rank-1 approximation of the SVD of the matrix $\left\{\log _{\mathrm{e}}[\mathrm{m}(\mathrm{x}, \mathrm{t})]-\mathrm{a}_{\mathrm{x}}\right\}$. Here, the success of long term forecasting totally depends on the goodness-of-fit of the rank-1 approximation.

2. Re-scaling $b_{x}$ and $k_{t}$ so that $b_{x}$ sum to unity and $k_{t}$ sum to 0 .

3. Adjusting $k_{t}$, the time-varying index, so that actual total number of deaths is equal to the fitted total number of deaths, for each $t$.

4. Modeling adjusted $k_{t}$ using standard time series approach.

5. Forecasting $k_{t}$, and hence $m(x, t)$, for future time periods, and finally

6. Constructing life tables and forecasting life expectancy at birth (or at specific ages). 


\subsection{Singular Value Decomposition (SVD) in the LC Approach}

Let $A$ be an $m \times k$ real matrix. Then there exists orthogonal matrices $U_{m \times m}$ and $V_{k \times k}$ such that $A=U \Lambda_{m \times k} V^{\prime}$ where $U^{\prime} U=I_{m}$ and $V^{\prime} V=I_{k}$. The ' $m$ ' columns of $U$ are the 'left singular vectors'; the ' $\mathrm{k}$ ' rows of $V$ ' are the 'right singular vectors'.

The normalized eigenvectors of $A A^{\prime}$ make up the columns of $U$ and the normalized eigenvectors of $A^{\prime} A$ make up the columns of $V$. The 'singular values' $\left(\lambda_{i}{ }^{\prime} s\right)$ in $\Lambda$ arranged in descending order, are the square roots of eigenvalues $\left(\lambda_{i}{ }^{2}\right)$ of $A A^{\prime}$ or $A^{\prime} A$, since they have the same eigenvalues (Good, 1969; Johnson and Wichern, 2002).

\section{Rank $\mathbf{r}$ approximation of SVD}

This is given by $A \approx U_{m \times r} \Lambda_{r \times r} V_{r \times k}^{\prime}$ where $U=\left(\underline{u}_{1}, \underline{u}_{2}, \ldots, \underline{u}_{r}\right)$; $V=\left(\underline{v}_{1}, \underline{v}_{2}, \ldots, \underline{v}_{r}\right)$ and $\Lambda$ is a diagonal matrix with the $r$ singular values $\lambda_{1}, \lambda_{2}, \ldots, \lambda_{r}$ along the diagonal in descending order. This can be written as $A=\lambda_{1} \underline{u}_{1} \underline{v}_{1}^{\prime}+\lambda_{2} \underline{u}_{2} \underline{v}_{2}^{\prime}+\ldots .+\lambda_{r} \underline{u}_{r} \underline{v}_{r}^{\prime}$.

Thus, rank-1 approximation of the SVD is $A \approx U_{1} \Lambda_{1} V_{1}^{\prime}$ where $U_{1}=\underline{u}_{1}$; $V_{1}=\underline{v}_{1}$ and $\Lambda_{1}=\lambda_{1}$ so that $A \approx \lambda_{1} \underline{u}_{1} \underline{v}_{1}^{\prime}$.

\section{SVD on MATLAB ${ }^{\circledR}$}

In MATLAB ${ }^{\circledR}$, $[U, S, V]=\operatorname{svd}(X)$

produces a diagonal matrix $S$ of the same dimensions as $X$ with non-negative diagonal elements in decreasing order, and $U \& V$ such that $U^{\prime} U=I_{m}$ and $V^{\prime} V=I_{k}$. $[U, S, V]=\operatorname{svd}(X, 0)$ produces 'economy size' decomposition. If $X$ is $m \times k$ with

$m>k$, then only the first $k$ columns of $U$ is printed and $S$ is $k \times k$ now. If $m<k$, $[U, S, V]=\operatorname{svd}(X$, 'econ') produces only the first m columns of $V$ and $S$ is $m \times m$ now. 


\section{Example}

Consider the following hypothetical example of $5 \times 3$ matrix of $m(x, t)$ values:

$$
A_{1}=\left[\begin{array}{lll}
.00930 & .00780 & .00665 \\
.00030 & .00027 & .00022 \\
.00018 & .00015 & .00013 \\
.00020 & .00017 & .00015 \\
.00065 & .00060 & .00057
\end{array}\right]
$$

Let $A$ be the matrix representing $\log _{e}[m(x, t)]$,

$$
\text { Then } A=\left[\begin{array}{lll}
-4.6777 & -4.8536 & -5.0131 \\
-8.1117 & -8.2171 & -8.4219 \\
-8.6225 & -8.8049 & -8.9480 \\
-8.5172 & -8.6797 & -8.8049 \\
-7.3385 & -7.4186 & -7.4699
\end{array}\right] \text {. }
$$

$[U, S, V]=\operatorname{svd}(A, 0)$ gives,

$$
\begin{aligned}
U & =\left[\begin{array}{ccc}
-.2805 & -.7755 & -.2260 \\
-.4772 & -.1062 & .8715 \\
-.5085 & -.0722 & -.3106 \\
-.5013 & .0849 & -.2738 \\
-.4285 & .6123 & -.1337
\end{array}\right] ; S=\left[\begin{array}{ccc}
29.9471 & 0 & 0 \\
0 & .1499 & 0 \\
0 & 0 & .0477
\end{array}\right] ; \text { and } \\
V & =\left[\begin{array}{lll}
.5671 & -.6971 & -.4387 \\
.5774 & -.0434 & .8153 \\
.5874 & .7157 & -.3779
\end{array}\right]
\end{aligned}
$$

Now, rank-1 approximation to SVD of A is given by

$$
A \approx(29.9471) \underline{u}_{1} \underline{v}_{1}^{\prime}=(29.9471)\left[\begin{array}{l}
-.2805 \\
-.4772 \\
-.5085 \\
-.5013 \\
-.4285
\end{array}\right]\left[\begin{array}{lll}
.5671 & .5774 & .5874
\end{array}\right] \text {. }
$$

The goodness-of-fit of this approximation is $=29.9471 / 30.1447=.99$, or $99 \%$ (where 30.1447 is the trace of $S$ ).

Now let $\quad \underline{b}_{X}=\frac{\underline{u}_{1}}{-2.1960}=\left[\begin{array}{llll}.1277 & .2173 .2316 .2283 .1951\end{array}\right]^{\prime} \quad$ where -

2.1960 is the sum of the elements of $\underline{u}_{1}$; Then, $\sum_{X} b_{X}=1$. 
Let $\underline{k}_{t}^{0}$ be equal to $(-2.1960)(29.9471) \underline{v}_{1}^{\prime}=\left[\begin{array}{llll}-37.2947 & -37.9720 & -38.6297\end{array}\right]$ which does not sum to 0 . But if we define $\bar{k}$ to be the mean of $\underline{k}_{t}^{0}$, then $\bar{k}=-37.9655$ and now $\underline{k}_{t}=\underline{k}_{t}^{0}-\bar{k}=\left[\begin{array}{lll}.6708 & -.0065 & -.6642\end{array}\right]$, so that $\sum_{t} \underline{k}_{t}=0$.

Thus, $A \approx \underline{b}_{x}\left(\underline{k}_{t}+\bar{k}\right)=\underline{b}_{x} \underline{k}_{t}+\bar{k} \underline{b}_{x}$ where $\bar{k} \underline{b}_{x}$ is equal to $\underline{a}_{x}$, so that the matrix $\log _{e}(m(x, t))-a_{x} \approx \underline{b}_{x} \underline{k}_{t}$ such that it satisfies the conditions of L-C model.

Lee and Miller (2001) make a careful assessment of the performance of LCmethod for forecasting mortality far into the future. They have not followed standard time series diagnostic methods to choose an optimum ARIMA model. Instead, they have assumed the random walk with a drift approach. According to Lee and Miller (2001), the LC-method still performed better than subjective expert judgment in most cases, but change in population ageing patterns, thus mortality rates in older populations, may pose problems for LC approach. Li et al (2004) discuss ways in which the LC approach can be used as a method to reduce the role of subjective judgment particularly in countries with limited data at unequal intervals.

In most applications to date, it has been found that a random walk with a drift (Lee and Carter, 1992) fits well though it is not always the best model overall. Unless some other time series model is found to be substantially better, it is advisable to use the random walk with drift because of its simplicity and straight forward interpretation.

\subsection{Life Tables}

A life table is simply an elegant and convenient way of analyzing age-specific death rates. The technique is now used in several other areas, where it is often called "survival analysis". Life tables answer many questions that cannot be answered with simple measures of rates and ratios. Questions of this nature have immense practical importance in many disciplines, such as education, health, insurance, and actuarial science. Life tables provide summary measures of the level of mortality, independent of the age composition which can therefore be used for comparing the mortality levels of different populations.

The basic inputs for construction of life tables are age-specific mortality rates from which all other columns are derived. The data required to obtain such mortality rates are, (i) the distribution of population by age and sex and, (ii) the distribution of deaths by age and sex. A complete life table contains data for 
every single year of age. An abridged life table, on the other hand, typically contains data by 5 -year age intervals.

The notations used for different columns of a life table is given below:

$\mathrm{x}$

$(\mathrm{x}, \mathrm{x}+\mathrm{n}) \quad$ : age group with initial age $\mathrm{x}$ with the length of interval $\mathrm{n}$

$\mathrm{m}(\mathrm{x}, \mathrm{n}) \quad:$ age - specific death rate for age interval $(\mathrm{x}, \mathrm{x}+\mathrm{n})$

$\mathrm{q}(\mathrm{x}, \mathrm{n}) \quad$ : probability of an individual aged $\mathrm{x}$ dying before the end of the interval $(\mathrm{x}, \mathrm{x}+\mathrm{n})$

$1(\mathrm{x}) \quad$ : number of survivors at age $\mathrm{x}$ in a life table with radix (starting population) of 100,000 persons

$\mathrm{d}(\mathrm{x}, \mathrm{n}) \quad$ : number of deaths in age interval $(\mathrm{x}, \mathrm{x}+\mathrm{n})$

$\mathrm{L}(\mathrm{x}, \mathrm{n}) \quad$ : number of person - years lived in age interval $(\mathrm{x}, \mathrm{x}+\mathrm{n})$

$\mathrm{S}(\mathrm{x}, \mathrm{n}) \quad$ : the proportion of the life table population in age group $(\mathrm{x}$, $\mathrm{x}+\mathrm{n}$ ) who are alive $\mathrm{n}$ years later.

$\mathrm{T}(\mathrm{x}) \quad$ : number of person - years lived at ages $\mathrm{x}$ and older.

$\mathrm{e}(\mathrm{x}) \quad$ : expectation of life at age $\mathrm{x}$, and

$a(x, n) \quad$ : average number of years lived in the age interval $(x, x+n)$ by those dying during that age interval.

Age-specific death rates are defined as:

$\mathrm{m}(\mathrm{x}, \mathrm{n})=\frac{\text { number of deaths in the age group }(\mathrm{x}, \mathrm{x}+\mathrm{n})}{\text { Population of the age group at mid interval }}$

Once the basic inputs are provided, the life tables can be calculated using most software packages. In this study, the freely downloadable software package MORTPAK $4^{\circledR 2}$ was used.

\section{Descriptive Analysis}

This section describes the data relating to population growth and the number of deaths registered in Sri Lanka from 1950 to 2008. Sex-specific death rates, considering both information of population and the number of death registered are also discussed.

\subsection{Population Growth}

Figure 3.1 shows the gender-wise midyear population 1950 up to 2010 (Source: Registrar General's Office and Department of Census and Statistics, Sri Lanka). Both have sharply upward trends, and the gap between the two graphs decrease

${ }^{2}$ See www.un.org/esa/population/mortpak/mortpakwebpage.pdf 
with time. From 1950 up to 2001, male population is greater than female population. After 2001, it is lower than the female population.

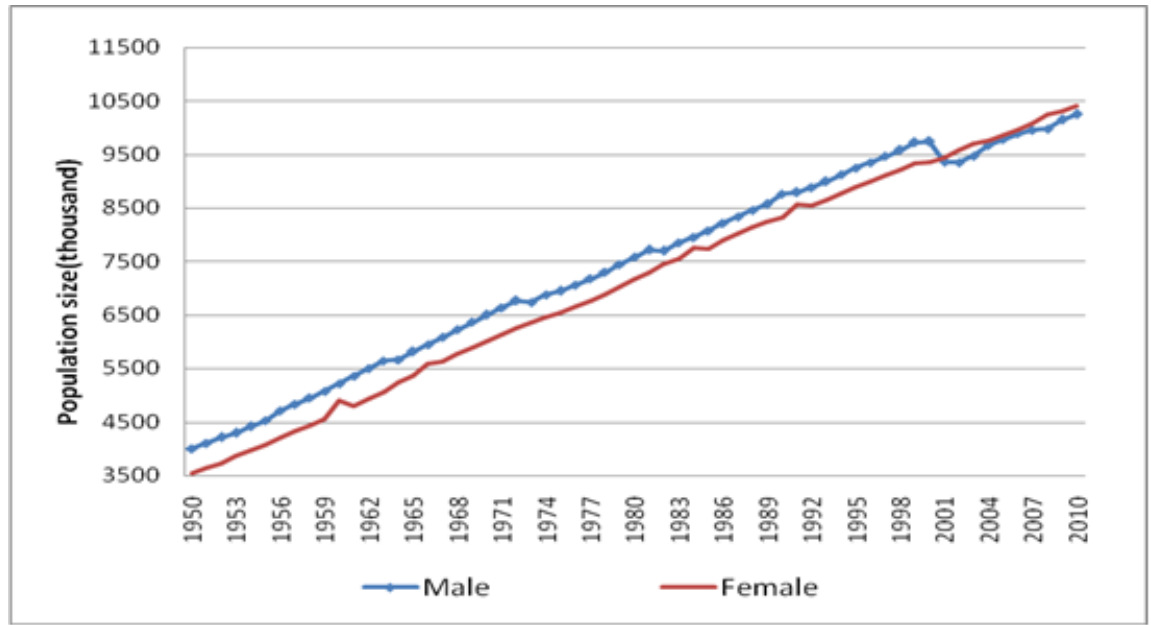

Figure 3.1: Time plot of midyear population size*

*Source: Department of Census and Statistics, Sri Lanka

Even though the Sri Lankan population size has been gradually increasing ( $7.54 \mathrm{~m}$ in 1950 to $20.2 \mathrm{~m}$ in 2010 ) the average annual growth rate is seen to be declining (3.0 in 1960 to 0.7 in 2010). An ageing population is commonly defined as one with an increasing proportion of the population in the elderly age groups. Table 3.1 (Source: Registrar General's Office and Department of Census and Statistics, Sri Lanka) clearly shows the changes in the percentage distribution of selected age groups.

Table 3.1: Percentage distribution of the population in selected age groups in Sri Lanka, for the period $1950-2010 *$

\begin{tabular}{|c|c|c|c|}
\hline \multirow{2}{*}{ Year } & \multicolumn{3}{|c|}{ Age group } \\
\cline { 2 - 4 } & $\mathbf{0 - 1 4}(\mathbf{\%})$ & $\mathbf{1 5 - 5 4}(\boldsymbol{\%})$ & $\mathbf{5 5}$ and above ( \% ) \\
\hline 1950 & 37.22 & 54.90 & 7.87 \\
\hline 1960 & 39.84 & 52.60 & 7.56 \\
\hline 1970 & 41.91 & 49.61 & 8.49 \\
\hline 1980 & 38.98 & 51.92 & 9.10 \\
\hline 1990 & 35.00 & 55.60 & 9.41 \\
\hline 2000 & 35.21 & 55.33 & 9.46 \\
\hline 2010 & 26.30 & 60.50 & 13.20 \\
\hline
\end{tabular}

*Source: Registrar General's Office, Department of Census and Statistics, Sri Lanka 
In Table 3.1 the elderly group is defined as those who are 55 years or more. The reason for this is that in both the government and private sectors in Sri Lanka, the retirement age falls between 55 and 60 years. According to Table 3.1, the elderly population is gradually increasing but the child population has increased up to 1970 and decreased thereafter. Middle age group has decreased up to 1970 and increased thereafter.

\subsection{Deaths}

The registered number of deaths reveals the effects of some historical events. Figure 3.2 shows that the number of male deaths is always greater than the number of female deaths. There are four peak points in 1974, 1989, 1996 and 2005 for the male graph but only two peak points in the female graph, namely 1974 and 2005. The reasons for these may be the effects of the youth unrests that occurred in 1971 and in 1987-89, the separatist war that took heavy tolls from time to time and especially an escalation of events in 1996, and the tsunami disaster that occurred in 2004 in the South, respectively. Except for the tsunami that took a mix of both male and female lives (with a higher proportion of females), the other events took mostly male lives.

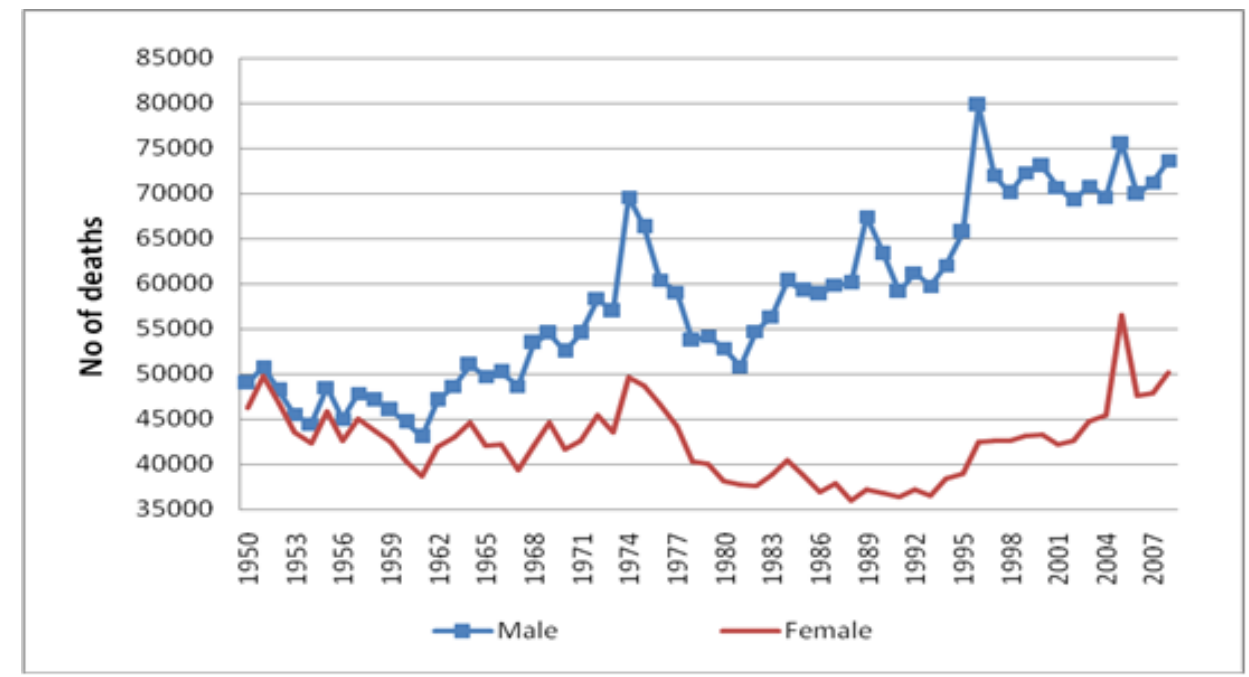

Figure 3.2: Time plot of gender wise total number of deaths*

*Source: Department of Census and Statistics, Sri Lanka 


\section{Results and Discussion}

\subsection{The LC model}

Rank-1 approximation to the exact SVD solution in the LC method was used for estimating $\mathrm{k}_{\mathrm{t}}, \mathrm{a}_{\mathrm{x}}$, and $\mathrm{b}_{\mathrm{x}}$ of equation (2.1) for both male and female data, as explained in Sections 2.2 and 2.3. The rank-1 approximation gave a goodnessof-fit of $91 \%$ and $89 \%$ for the female and male data respectively. Table 4.1 shows the estimates of $a_{x}$ and $b_{x}$ for both sexes for the period $1950-2008$.

Table 4.1: Estimates of $a_{x}$ and $b_{x}$ for $1950-2008$ for males and females

\begin{tabular}{|c|c|c|c|c|}
\hline \multirow{2}{*}{ Age Group } & \multicolumn{2}{|c|}{ Males } & \multicolumn{2}{c|}{ Females } \\
\cline { 2 - 5 } & $\mathrm{a}_{\mathrm{x}}$ & $\mathrm{b}_{\mathrm{x}}$ & $\mathrm{a}_{\mathrm{x}}$ & $\mathrm{b}_{\mathrm{x}}$ \\
\hline $0-4$ & -4.68823 & 0.05897 & -4.82197 & 0.05702 \\
$5-9$ & -6.78061 & 0.08529 & -6.80158 & 0.08043 \\
$10-14$ & -7.06443 & 0.08886 & -7.19796 & 0.08512 \\
$15-19$ & -6.51973 & 0.08201 & -6.66236 & 0.07879 \\
$20-24$ & -6.05618 & 0.07617 & -6.41775 & 0.07590 \\
$25-29$ & -5.94682 & 0.07480 & -6.32310 & 0.07478 \\
$30-34$ & -5.87618 & 0.07391 & -6.21934 & 0.07355 \\
$35-39$ & -5.54524 & 0.06975 & -5.99724 & 0.07092 \\
$40-44$ & -5.28597 & 0.06649 & -5.82504 & 0.06889 \\
$45-49$ & -4.89645 & 0.06159 & -5.47108 & 0.06470 \\
$50-54$ & -4.57742 & 0.05757 & -5.11910 & 0.06054 \\
$55-59$ & -4.15225 & 0.05223 & -4.65699 & 0.05507 \\
$60-64$ & -3.82528 & 0.04811 & -4.24522 & 0.05020 \\
$65-69$ & -3.33825 & 0.04199 & -3.63993 & 0.04305 \\
$70-74$ & -2.91610 & 0.03668 & -3.10025 & 0.03666 \\
75 and over & -2.03447 & 0.02559 & -2.06112 & 0.02437 \\
\hline
\end{tabular}

The plot of adjusted $k_{t}$ for the period 1950 - 2008 along with 30 year forecasts with $95 \%$ confidence bands for both sexes (with ' $\mathrm{K}_{\mathrm{t}}^{(\mathrm{m})}$ ), for males and ' $\mathrm{K}_{\mathrm{t}}^{(\mathrm{f})}$, for females) is shown in Figure 4.1(a) and 4.1(b) respectively. The forecasts were made using the models that performed better than the others considered (i.e. VAR model). One striking observation that was made from these forecasts was that even though the adjusted $\mathrm{k}_{\mathrm{t}}$ series generally showed a downward trend in both graphs in agreement with that of LC for their study period, the forecasts for the 
period $2010-2030$ showed a slightly upward trend. This upward trend is probably a result of the increase in the mortality index from 2000 to 2001 in both graphs, Figure 4.1(a) and 4.1(b).

(a) Adjusted $\mathrm{k}_{\mathrm{t}}$ for males with forecasts

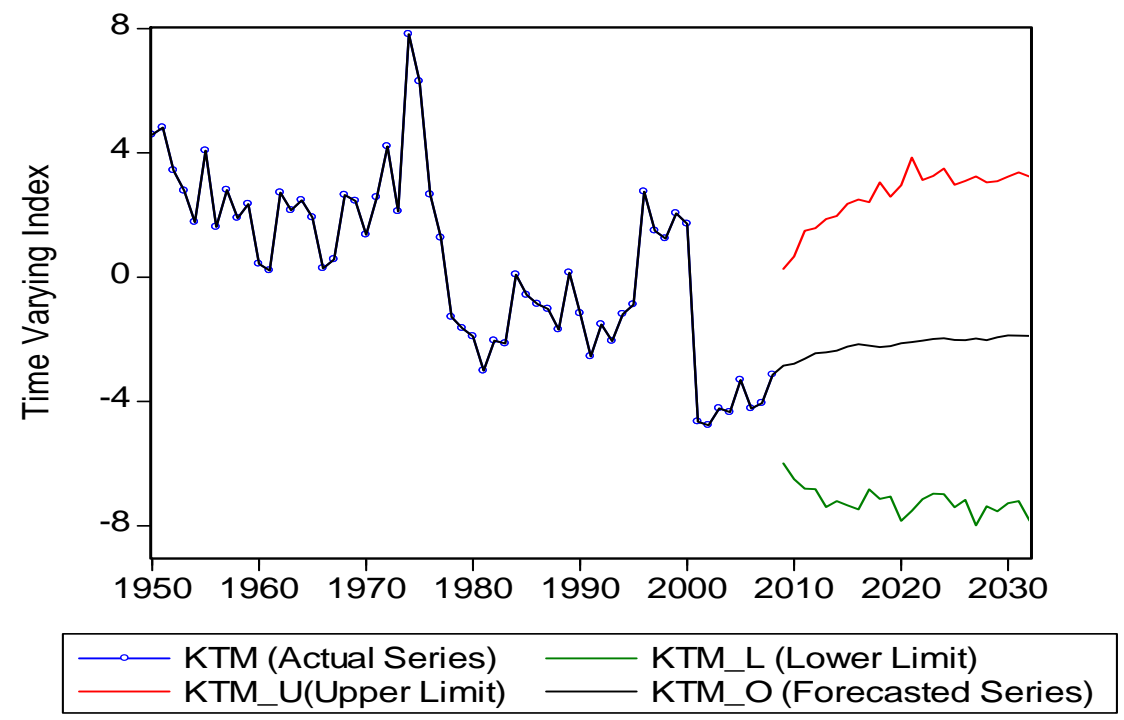

(b) Adjusted $\mathrm{k}_{\mathrm{t}}$ for females with forecasts

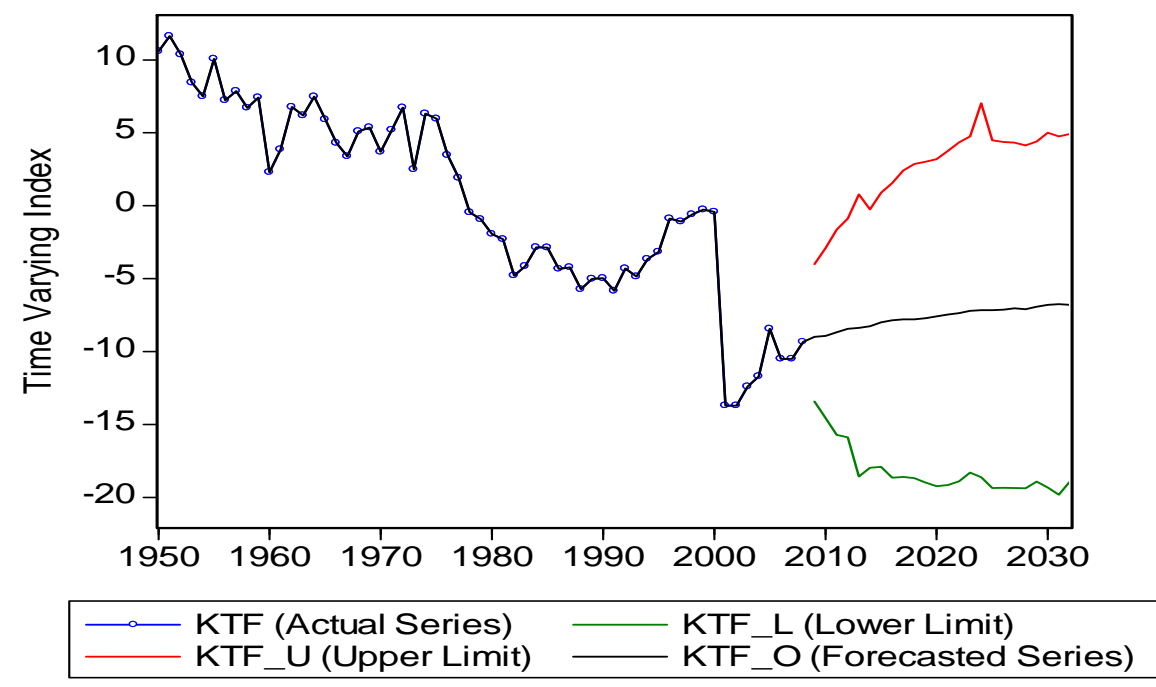

Figure 4.1: Adjusted time-varying index $\left(\mathrm{k}_{\mathrm{t}}\right)$ for both males and females with forecasts. 
Therefore, year 2001 looked like a turning point in our data set; however, this may be a short term turn and as we move on to the future when new data are available, the updated picture may be consistent with the general downward trend of LC. However, the lower bound of the 95\% confidence interval based on the VAR model in both graphs 4.1(a) and 4.1(b), showed a downward trend over the period 2010 - 2030 indicating a possibility for the actual forecasts to follow the usually expected downward trend. These will be further discussed in Section 4.2.

\subsection{Modeling Adjusted $\mathbf{k}_{\mathbf{t}}$ Series}

In our case, the adjusted $k_{t}$ series (i.e. the time varying index) for both males (denoted by $\mathrm{K}_{\mathrm{t}}^{(\mathrm{m})}$ ) and females (denoted by $\mathrm{K}_{\mathrm{t}}^{(\mathrm{f})}$ ), were modeled using a standard time series approach. First of all, the augmented Dickey-Fuller unit root test (Dickey and Fuller, 1979) was applied to the two series, and it was found that the two series were integrated of order 1 . After finding the order of differencing, ARIMA models were fitted to both series using the package EVIEWS ${ }^{\circledR}$ and based on Akaike Information Criterion (AIC), it was found that ARIMA $(1,1,1)$ had the least AIC values for both male data $(\mathrm{AIC}=3.89)$ and female data $(\mathrm{AIC}=$ 4.54). However, model adequacy tests failed to accept ARIMA $(1,1,1)$ as a suitable model in both cases. Therefore, the two series were first modeled using a random walk with drift as well as random walk with drift in the presence of intervention, though the random walk models were not the best fitted. This was done in view of higher residuals at 1974 and 2001 for $\mathrm{K}_{\mathrm{t}}^{(\mathrm{m})}$ series and at 2001 for $\mathrm{K}_{\mathrm{t}}^{(\mathrm{f})}$ series, by following an approach similar to that of Lee and Carter (1992). Then a vector autoregressive (VAR) model that combines data from both series was fitted to first differenced series anticipating better results, and thus forecasts. These fitted models are shown below:

\section{Random Walk Models for $\mathbf{K}_{\mathbf{t}}^{(\mathbf{m})}$ Series:}

(with drift):

$$
\mathbf{K}_{\mathbf{t}}^{(\mathbf{m})}-\mathbf{K}_{\mathbf{t}-1}{ }^{(\mathbf{m})}=-0.1331
$$

(with drift and intervention at 1974 and 2001):

$$
\mathbf{K}_{\mathbf{t}}^{(\mathbf{m})}-\mathbf{K}_{\mathbf{t}-1}{ }^{(\mathbf{m})}=-0.1261-0.2029 * \mathrm{WT}
$$

where WT $=1$, when year $=1974$ or 2001; and 0 otherwise. 


\section{Random Walk Models for $\mathbf{K}_{\mathbf{t}}^{(\mathbf{f})}$ Series:}

(with drift):

$$
\mathbf{K}_{\mathbf{t}}^{(\mathbf{f})}-\mathbf{K}_{\mathbf{t}-1}^{(\mathbf{f})}=-0.3436
$$

(with drift and intervention at 2001) :

$$
\mathbf{K}_{\mathbf{t}}^{(\mathbf{f})}-\mathbf{K}_{\mathbf{t}-\mathbf{1}}^{(\mathbf{f})}=-0.1167-13.1633 * \mathrm{PT}
$$

Where PT $=1$, when year $=2001$; and 0 , otherwise.

VAR models, traditionally designed for stationary series, have proven to be especially useful for dynamic forecasting of economic and financial time series and usually provide superior forecasts to those from univariate time series models under certain conditions. Recent studies show that VAR models have been used for mortality modeling as well. When there is no cointegration, standard VAR models are usually used whereas Error Corrected VAR models (VEC) are used in the presence of cointegration (Lütkepohl, 2005). Due to Lütkepohl (2005), VAR models can also be used when the cointegration structure is unknown. Since the order of integration was 1 in both series and there was no cointegration, standard VAR models were fitted to the vector of first differenced series using EVIEWS ${ }^{\circledR}$ package. The form of the VAR model was such that each variable has an equation explaining its evolution based on its own lags and the lags of the other variable (lag 1 in our case) and the fitted models (in terms of the current series) are shown below:

VAR Model for $\mathbf{K}_{\mathrm{t}}^{(\mathrm{m})}$ Series:

$$
\mathbf{K}_{\mathbf{t}}{ }^{(\mathbf{m})}=0.1454 * \mathbf{K}_{\mathbf{t}-1}{ }^{(\mathbf{f})}+0.4990 * \mathbf{K}_{\mathbf{t}-1}{ }^{(\mathbf{m})}+0.0552
$$

Standard errors of the coefficients in model (4.5) are .0715, .1672, and .2230 respectively and $\mathrm{R}^{2}$ was $67 \%$.

\section{VAR Model for $k_{t} f$ Series:}

$$
\mathbf{K}_{\mathbf{t}}^{(\mathbf{f})}=1.0592 * \mathbf{K}_{\mathbf{t}-1}{ }^{(\mathbf{f})}-0.3432 * \mathbf{K}_{\mathbf{t}-1}{ }^{(\mathbf{m})}-0.1981
$$

Standard errors of the coefficients in model (4.6) are $.1045, .2445$, and .3260 respectively. The goodness-of-fit given by the $\mathrm{R}^{2}$ was $87 \%$. As we have observed from the beginning, the female series was much smoother than the male one and the SVD gave a better fit (91\%) for the female data than for the male data (89\%). This is further confirmed here for the fitting of VAR models. As a result more accurate forecasts are anticipated for female data than for male data in our study. 
The models (4.5) and (4.6) did not show any notable violations of the diagnostics and it looked like the problem that arose with higher residuals at given years in the random walk models are now taken care of by the VAR models. Therefore, models (4.5) and (4.6) were used for forecasting in our study.

\subsection{Calculation of Death Rates}

For both male and female models that were fitted, $\ln [\mathrm{m}(\mathrm{x}, \mathrm{t})]$, i.e. the logarithm of the death rate, was calculated using the following equation:

$$
\ln [\hat{m}(x, t)]=a_{x}+b_{x} \hat{k}_{t}
$$

where estimates of $a_{\mathrm{x}}$ and $b_{\mathrm{x}}$ are obtained from Table 4.1, and $\mathrm{k}_{\mathrm{t}}$ from equations (4.1) - (4.6). Figure 4.2 shows a comparison of actual death rates (in logarithm scale) for the years 1950, 1975, and 2000 with the forecasts for 2025 using model (4.5) for the male series.

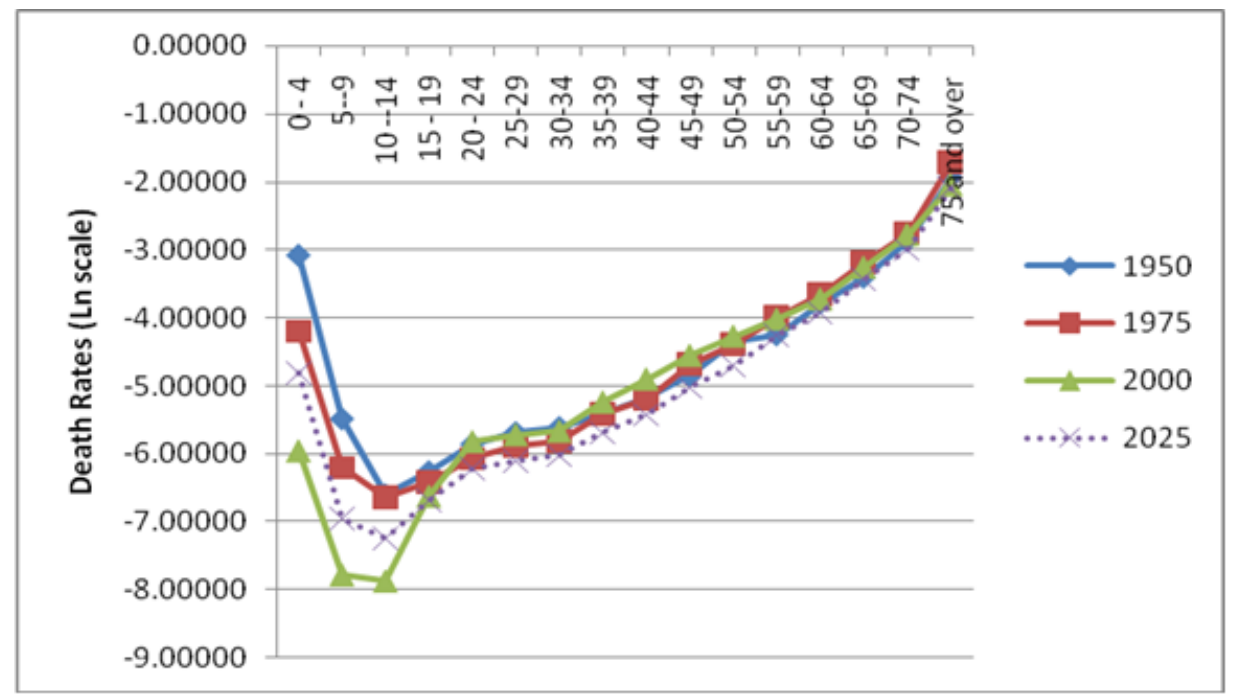

Figure 4.2: Comparison of actual and forecast death rates by age for males, at selected years (actual values in solid and forecasts in dots).

The goodness-of-fit of model (4.5) was tested using $\mathrm{R}^{2}$ which was $67 \%$. It was observed that the forecasts for 2025 given by (4.5) matched the overall shape of actual death rates in log scale for the given years 1950, 1975, and 2000 over the age groups well. In fact, the forecasts for 2025 were between those for 1975 and 2000 in the age groups $0-4,5-9$, and $10-14$ and were very close (lying slightly lower) to those of 1950,1975 , and 2000 in all other age groups. 
Figure 4.3 shows a comparison of actual death rates (in logarithm scale) for the years 1950, 1975, and 2000 with the forecasts for 2025 using model (4.6) for the female series.

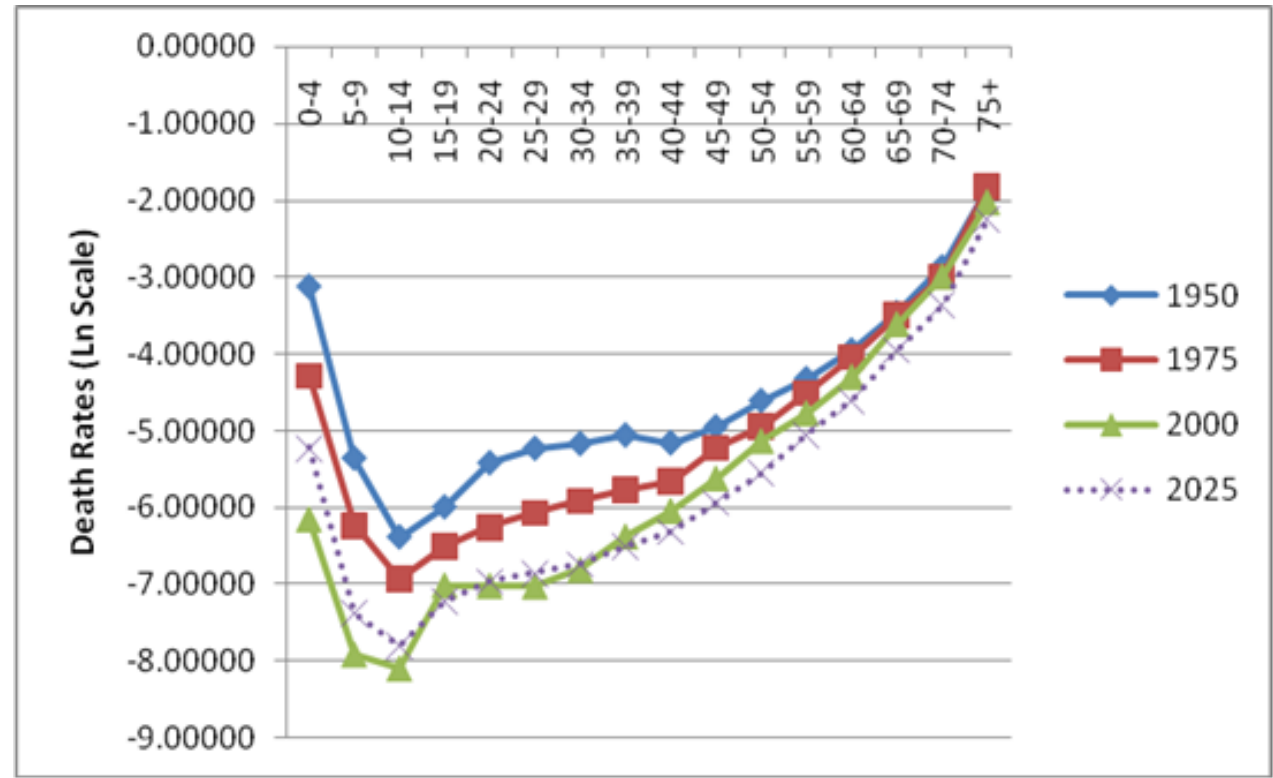

Figure 4.3: Comparison of actual and forecast death rates by age for females, at selected years (actual values in solid and forecasts in dots)

The goodness-of-fit of model (4.6) was tested using $\mathrm{R}^{2}$ which was $87 \%$. It was observed that the forecasts for 2025 given by (4.6) matched the overall shape of actual death rates in $\log$ scale for the given years 1950, 1975, and 2000 over the age groups well. In fact, the forecasts for 2025 were between those for 1975 and 2000 in the age groups $0-4,5-9$, and $10-14$ and were almost equal to those of 2000 in the age groups $15-19,20-24,25-29$, and $30-34$; and were lying slightly below those of 2000 in all other age groups.

\subsection{Calculation of Life Tables}

Abridged life tables were generated using actual data for a selected period, namely 2006 - 2008 using the software package MORTPAK4 ${ }^{\circledR}$. Tables 4.2 and 4.3 show these generated life tables for the male and the female data respectively. In these tables, age-specific death rates were obtained for individual ages $0,1,5,10, \ldots, 75,80$, and 85 , in the given period. 
Table 4.2: Abridged life tables for males for the period 2006 - 2008 using actual death rates

\begin{tabular}{|r|c|c|c|r|r|r|r|r|r|}
\hline \multicolumn{7}{|c|}{ Life table for males $2006-2008$} \\
\hline Age & $\mathrm{m}(\mathrm{x}, \mathrm{n})$ & $\mathrm{q}(\mathrm{x}, \mathrm{n})$ & $\mathrm{l}(\mathrm{x})$ & $\mathrm{d}(\mathrm{x}, \mathrm{n})$ & $\mathrm{L}(\mathrm{x}, \mathrm{n})$ & $\mathrm{S}(\mathrm{x}, \mathrm{n})$ & $\mathrm{T}(\mathrm{x})$ & $\mathrm{e}(\mathrm{x})$ & $\mathrm{a}(\mathrm{x}, \mathrm{n})$ \\
\hline 0 & 0.01098 & 0.01087 & 100000 & 1087 & 98994 & 0.98818 & 7035232 & 70.352 & 0.074 \\
\hline 1 & 0.00059 & 0.00237 & 98913 & 234 & 395097 & 0.99777 & 6936238 & 70.124 & 1.620 \\
\hline 5 & 0.00033 & 0.00165 & 98679 & 163 & 492989 & 0.99835 & 6541142 & 66.287 & 2.500 \\
\hline 10 & 0.00033 & 0.00164 & 98516 & 161 & 492177 & 0.99740 & 6048153 & 61.393 & 2.500 \\
\hline 15 & 0.00082 & 0.00410 & 98355 & 403 & 490899 & 0.99402 & 5555975 & 56.489 & 2.829 \\
\hline 20 & 0.00160 & 0.00796 & 97952 & 780 & 487962 & 0.99046 & 5065077 & 51.710 & 2.698 \\
\hline 25 & 0.00215 & 0.01072 & 97171 & 1041 & 483308 & 0.98940 & 4577115 & 47.103 & 2.552 \\
\hline 30 & 0.00210 & 0.01043 & 96130 & 1003 & 478187 & 0.98832 & 4093807 & 42.586 & 2.543 \\
\hline 35 & 0.00270 & 0.01342 & 95127 & 1277 & 472601 & 0.98407 & 3615620 & 38.008 & 2.621 \\
\hline 40 & 0.00386 & 0.01912 & 93851 & 1794 & 465070 & 0.97539 & 3143019 & 33.490 & 2.668 \\
\hline 45 & 0.00628 & 0.03095 & 92057 & 2849 & 453624 & 0.96318 & 2677949 & 29.090 & 2.662 \\
\hline 50 & 0.00895 & 0.04384 & 89208 & 3911 & 436920 & 0.94204 & 2224325 & 24.934 & 2.669 \\
\hline 55 & 0.01543 & 0.07447 & 85296 & 6352 & 411597 & 0.91058 & 1787405 & 20.955 & 2.657 \\
\hline 60 & 0.02216 & 0.10523 & 78944 & 8307 & 374790 & 0.87652 & 1375808 & 17.428 & 2.601 \\
\hline 65 & 0.03126 & 0.14536 & 70637 & 10268 & 328511 & 0.82251 & 1001017 & 14.171 & 2.597 \\
\hline 70 & 0.04824 & 0.21593 & 60369 & 13036 & 270203 & 0.74485 & 672507 & 11.140 & 2.573 \\
\hline 75 & 0.07174 & 0.30503 & 47334 & 14438 & 201261 & 0.61985 & 402304 & 8.499 & 2.548 \\
\hline 80 & 0.12430 & 0.47138 & 32895 & 15506 & 124752 & 0.37947 & 201043 & 6.112 & 2.438 \\
\hline 85 & 0.22793 & $\ldots$ & 17389 & 17389 & 76291 & $\ldots$ & 76291 & 4.387 & 4.387 \\
\hline
\end{tabular}

In Table 4.2, the first entry of $\mathrm{S}(\mathrm{x}, \mathrm{n})$ is for survivorship of 5 cohorts of birth to age group $0-4=\mathrm{L}(0,5) / 500000$. Second entry of $S(x, n)$ is for, $\mathrm{S}(0,5)=\mathrm{L}(5,5) / \mathrm{L}(0,5)$, and the last entry of $\mathrm{S}(\mathrm{x}, \mathrm{n})$ is $\mathrm{S}(80+, 5)=\mathrm{T}(85) / \mathrm{T}(80)$. 
Table 4.3: Abridged life tables for females for the period 2006 - 2008 using actual death rates

\begin{tabular}{|r|c|c|c|c|c|c|c|c|r|}
\hline \multicolumn{10}{|c|}{ Life table for females $2006-2008$} \\
\hline Age & $\mathrm{m}(\mathrm{x}, \mathrm{n})$ & $\mathrm{q}(\mathrm{x}, \mathrm{n})$ & $\mathrm{l}(\mathrm{x})$ & $\mathrm{d}(\mathrm{x}, \mathrm{n})$ & $\mathrm{L}(\mathrm{x}, \mathrm{n})$ & $\mathrm{S}(\mathrm{x}, \mathrm{n})$ & $\mathrm{T}(\mathrm{x})$ & $\mathrm{e}(\mathrm{x})$ & $\mathrm{a}(\mathrm{x}, \mathrm{n})$ \\
\hline 0 & 0.00891 & 0.00884 & 100000 & 884 & 99184 & 0.99032 & 7685034 & 76.850 & 0.077 \\
\hline 1 & 0.00049 & 0.00197 & 99116 & 195 & 395978 & 0.99819 & 7585850 & 76.535 & 1.510 \\
\hline 5 & 0.00028 & 0.00137 & 98921 & 136 & 494264 & 0.99865 & 7189872 & 72.683 & 2.500 \\
\hline 10 & 0.00026 & 0.00132 & 98785 & 131 & 493597 & 0.99821 & 6695609 & 67.780 & 2.500 \\
\hline 15 & 0.00048 & 0.00241 & 98654 & 238 & 492713 & 0.99739 & 6202012 & 62.866 & 2.651 \\
\hline 20 & 0.00055 & 0.00274 & 98417 & 270 & 491429 & 0.99688 & 5709299 & 58.012 & 2.576 \\
\hline 25 & 0.00070 & 0.00349 & 98147 & 343 & 489896 & 0.99647 & 5217870 & 53.164 & 2.554 \\
\hline 30 & 0.00072 & 0.00358 & 97804 & 350 & 488166 & 0.99598 & 4727974 & 48.341 & 2.556 \\
\hline 35 & 0.00092 & 0.00459 & 97454 & 447 & 486205 & 0.99472 & 4239808 & 43.506 & 2.614 \\
\hline 40 & 0.00125 & 0.00622 & 97007 & 603 & 483636 & 0.99169 & 3753603 & 38.694 & 2.678 \\
\hline 45 & 0.00219 & 0.01088 & 96404 & 1049 & 479617 & 0.98629 & 3269967 & 33.919 & 2.707 \\
\hline 50 & 0.00345 & 0.01710 & 95355 & 1630 & 473043 & 0.97689 & 2790350 & 29.263 & 2.710 \\
\hline 55 & 0.00619 & 0.03051 & 93725 & 2859 & 462112 & 0.95948 & 2317307 & 24.724 & 2.722 \\
\hline 60 & 0.01065 & 0.05197 & 90866 & 4722 & 443387 & 0.93575 & 1855195 & 20.417 & 2.683 \\
\hline 65 & 0.01656 & 0.07978 & 86144 & 6872 & 414898 & 0.88805 & 1411807 & 16.389 & 2.698 \\
\hline 70 & 0.03252 & 0.15117 & 79271 & 11983 & 368452 & 0.81312 & 996909 & 12.576 & 2.671 \\
\hline 75 & 0.05222 & 0.23249 & 67288 & 15644 & 299595 & 0.67766 & 628458 & 9.340 & 2.645 \\
\hline 80 & 0.10984 & 0.43179 & 51644 & 22300 & 203024 & 0.38265 & 328863 & 6.368 & 2.525 \\
\hline 85 & 0.23319 & $\ldots$ & 29345 & 29345 & 125839 & $\ldots$ & 125839 & 4.288 & 4.288 \\
\hline
\end{tabular}

In Table 4.3, the first entry of $\mathrm{S}(\mathrm{x}, \mathrm{n})$ is for survivorship of 5 cohorts of birth to age group $0-4=\mathrm{L}(0,5) / 500000$. The second entry of $\mathrm{S}(\mathrm{x}, \mathrm{n})$ is for $\mathrm{S}(0,5)=$ $\mathrm{L}(5,5) / \mathrm{L}(0,5)$, and

last entry of $\mathrm{S}(\mathrm{x}, \mathrm{n})$ is $\mathrm{S}(80+, 5)=\mathrm{T}(85) / \mathrm{T}(80)$.

\section{Outcomes of the life tables}

From Tables 4.2 and 4.3 that were based on 2006 - 2008 data, it appears that the life expectancy at birth for males in Sri Lanka is 70.3 years while for females it is 76.8 years. The column $\mathrm{q}(\mathrm{x}, \mathrm{n})$ can be used for calculating the probability of an individual aged $\mathrm{x}$ surviving another $\mathrm{n}$ years (where $\mathrm{n}$ is the considered age group size). This probability gives important information as input for state sector decision makers as well as private sector financial institutions. For example, the probability that a 50-year old male surviving another 5 years is $(1-\mathrm{q}(50,5))=$ 1 - $0.04384=0.95616$ from Table 4.2. A similar probability for a 50 -year old female is $=1-0.01710=0.9829$ from Table 4.3. 
One may also be able to calculate the probability of a person aged $\mathrm{x}$ surviving a longer period than $n$ years, especially a period which is a multiple of $n$, using information from the life tables.

For example, the probability of a male aged 55 years surviving another 20 years $\left({ }_{20} \mathrm{p}_{55}\right.$, say) may be of interest to many financial institutions. Using the fact that events are independent, it can be calculated from Table 4.2, as follows:

${ }_{20} \mathrm{p}_{55}=\left(1-{ }_{5} \mathrm{q}_{55}\right)\left(1-{ }_{5} \mathrm{q}_{60}\right)\left(1-{ }_{5} \mathrm{q}_{65}\right)=(0.92553)(0.89477)(0.85464)=0.71$.

A similar probability for a female aged 55 years is

$=(0.96945)(0.94803)(0.92022)=0.85$.

\subsection{Mortality Forecasts}

Using the VAR models that were considered as the best fitted in our study, relatively accurate mortality forecasts (i.e. forecasts of time-varying index $\mathrm{k}_{\mathrm{t}}$ ) can be made for males as well as females using the two fitted models (4.5) and (4.6) respectively, on the assumption that conditions that prevailed during the study period will not drastically change over the forecast period. This attempt of forecasting for 30 years ahead depends on the ability of the rank-1 approximation to SVD to capture the trend in the (adjusted) mortality index $k_{t}$ for both sexes. On the other hand, even though they were not the best fitting models, random walk models with drift (with and without intervention) were also used for forecasting mortality index. A comparison of forecasts using VAR models and random walk models for both series, male and female, are given in Tables 4.4 and 4.5. It seems that the widths of $95 \%$ confidence intervals for the forecasts from the random walk models (with or without intervention) appear to be unacceptably high when compared to those from the VAR models in both Tables 4.4 and 4.5. The confidence intervals for the forecasts during the period 2010 - 2030 obtained from the VAR models appear to be relatively more accurate even though the forecasts showed a slightly upward trend during the forecast period as discussed in section 4.1. 
Table 4.4: Comparison of forecasts along with Lower Limit (L.L.) and Upper Limit (U.L.) of $95 \%$ Confidence Intervals for mortality index $\left(\mathrm{K}_{\mathrm{t}}^{(\mathrm{m})}\right)$ for male data (2009-2032) using three different methods

\begin{tabular}{|c|c|c|c|c|c|c|c|c|c|}
\hline \multirow[b]{2}{*}{ Period } & \multicolumn{3}{|c|}{ Method1 $^{3}$} & \multicolumn{3}{|c|}{ Method2 $^{4}$} & \multicolumn{3}{|c|}{ Method3 $^{5}$} \\
\hline & Forecast & L.L & U.L & Forecast & L.L & U.L & Forecast & L.L & U.L \\
\hline 2009 & -3.27312 & -30.3411 & 23.79488 & -2.89594 & -6.13464 & 0.125302 & -3.26613 & -30.5686 & 24.03635 \\
\hline 2010 & -3.40624 & -30.7027 & 23.89018 & -2.76359 & -6.68348 & 1.405362 & -3.39225 & -30.9251 & 24.14063 \\
\hline 2011 & -3.53936 & -31.0623 & 23.98359 & -2.57093 & -6.61885 & 1.787354 & -3.51838 & -31.2798 & 24.243 \\
\hline 2012 & -3.67248 & -31.4201 & 24.07515 & -2.48342 & -7.14966 & 1.936723 & -3.6445 & -31.6325 & 24.3435 \\
\hline 2013 & -3.8056 & -31.7761 & 24.16491 & -2.44648 & -7.07417 & 2.197774 & -3.77063 & -31.9834 & 24.44218 \\
\hline 2014 & -3.93872 & -32.1304 & 24.2529 & -2.41709 & -7.12387 & 1.645799 & -3.89675 & -32.3326 & 24.53909 \\
\hline 2015 & -4.07185 & -32.4829 & 24.33917 & -2.43113 & -7.09737 & 2.072679 & -4.02288 & -32.68 & 24.63425 \\
\hline 2016 & -4.20497 & -32.8337 & 24.42377 & -2.39395 & -6.9072 & 1.915434 & -4.149 & -33.0257 & 24.72773 \\
\hline 2017 & -4.33809 & -33.1829 & 24.50671 & -2.24717 & -7.47018 & 2.40013 & -4.27513 & -33.3698 & 24.81954 \\
\hline 2018 & -4.47121 & -33.5305 & 24.58806 & -2.25574 & -7.70979 & 2.565054 & -4.40125 & -33.7122 & 24.90974 \\
\hline 2019 & -4.60433 & -33.8765 & 24.66783 & -2.24312 & -7.39284 & 2.595807 & -4.52738 & -34.0531 & 24.99835 \\
\hline 2020 & -4.73745 & -34.221 & 24.74606 & -2.12235 & -7.04576 & 2.869309 & -4.6535 & -34.3924 & 25.08541 \\
\hline 2021 & -4.87057 & -34.5639 & 24.82279 & -2.14778 & -7.37227 & 2.993446 & -4.77963 & -34.7302 & 25.17095 \\
\hline 2022 & -5.00369 & -34.9054 & 24.89805 & -2.12024 & -7.6964 & 2.475982 & -4.90575 & -35.0665 & 25.25501 \\
\hline 2023 & -5.13681 & -35.2455 & 24.97186 & -2.03951 & -7.18069 & 3.082094 & -5.03188 & -35.4014 & 25.33761 \\
\hline 2024 & -5.26993 & -35.5841 & 25.04426 & -2.01613 & -7.31247 & 3.050106 & -5.158 & -35.7348 & 25.41879 \\
\hline 2025 & -5.40305 & -35.9214 & 25.11528 & -1.96135 & -7.64126 & 3.549703 & -5.28413 & -36.0668 & 25.49857 \\
\hline 2026 & -5.53617 & -36.2573 & 25.18494 & -1.94547 & -7.09025 & 3.163079 & -5.41025 & -36.3975 & 25.57698 \\
\hline 2027 & -5.66929 & -36.5919 & 25.25327 & -1.92611 & -7.34813 & 3.414653 & -5.53638 & -36.7268 & 25.65406 \\
\hline 2028 & -5.80241 & -36.9251 & 25.3203 & -1.97274 & -7.28994 & 3.143004 & -5.6625 & -37.0548 & 25.72981 \\
\hline 2029 & -5.93553 & -37.2571 & 25.38605 & -1.9846 & -7.13241 & 3.387059 & -5.78863 & -37.3815 & 25.80428 \\
\hline 2030 & -6.06866 & -37.5879 & 25.45054 & -1.98787 & -7.0372 & 3.359687 & -5.91475 & -37.707 & 25.87748 \\
\hline 2031 & -6.20178 & -37.9174 & 25.5138 & -1.92232 & -7.10972 & 3.234121 & -6.04088 & -38.0312 & 25.94944 \\
\hline 2032 & -6.3349 & -38.2457 & 25.57586 & -1.83974 & -7.2004 & 3.405044 & -6.167 & -38.3542 & 26.02018 \\
\hline
\end{tabular}

${ }^{3}$ Random Walk Model with Drift : $\mathbf{K}_{\mathrm{t}}^{(\mathrm{m})}-\mathbf{K}_{\mathrm{t}-1}^{(\mathrm{m})}=-0.133121$

4 Vector Autoregressive (VAR) Model: $\mathbf{K}_{\mathrm{t}}{ }^{(\mathbf{m})}=0.145375603 * \mathbf{K}_{\mathrm{t}-1}{ }^{(\mathbf{f})}+$ $0.4989909555 * \mathbf{K}_{\mathrm{t}-1}{ }^{(\mathrm{m})}+0.05517314328$

${ }^{5}$ Random Walk Model with Drift + Dummy Variable $: \mathbf{K}_{\mathbf{t}}^{(\mathbf{m})}-\mathbf{K}_{\mathrm{t}-1}{ }^{(\mathrm{m})}=-0.126125-$ $0.202875 *$ WT where WT $=1$ for year $=1974$ and year $=2001$ and 0 otherwise 
Table 4.5: Comparison of forecasts along with Lower Limit (L.L.) and Upper Limit (U.L.) of $95 \%$ Confidence Intervals for mortality index $\left(\mathrm{K}_{\mathrm{t}}{ }^{(\mathrm{f})}\right)$ for female data (2009-2032) using three different methods

\begin{tabular}{|c|c|c|c|c|c|c|c|c|c|}
\hline \multirow[b]{2}{*}{ Period } & \multicolumn{3}{|c|}{ Method1 $^{6}$} & \multicolumn{3}{|c|}{ Method2 $^{7}$} & \multicolumn{3}{|c|}{ Method3 $^{8}$} \\
\hline & Forecast & L.L & U.L & Forecast & L.L & U.L & Forecast & L.L & U.L \\
\hline 2009 & 17.55644 & -20.2753 & 55.38813 & 88.03428 & 60.85152 & 115.217 & -9.04252 & -13.4617 & -4.76413 \\
\hline 2010 & 17.67451 & -20.4765 & 55.82547 & 89.57 & 62.16153 & 116.9785 & -8.87906 & -15.1067 & -1.50658 \\
\hline 2011 & 17.79259 & -20.675 & 56.26016 & 91.10572 & 63.47338 & 118.7381 & -8.57138 & -15.8173 & -1.35777 \\
\hline 2012 & 17.91066 & -20.8709 & 56.69226 & 92.64144 & 64.78703 & 120.4959 & -8.40689 & -16.2469 & 0.61996 \\
\hline 2013 & 18.02874 & -21.0644 & 57.12184 & 94.17717 & 66.10243 & 122.2519 & -8.36354 & -16.9413 & 0.218174 \\
\hline 2014 & 18.14681 & -21.2553 & 57.54895 & 95.71289 & 67.41955 & 124.0062 & -8.21932 & -17.8451 & 0.316045 \\
\hline 2015 & 18.26489 & -21.4439 & 57.97366 & 97.24861 & 68.73835 & 125.7589 & -8.21429 & -18.1698 & 0.971324 \\
\hline 2016 & 18.38296 & -21.6301 & 58.39603 & 98.78433 & 70.05878 & 127.5099 & -8.15736 & -17.9066 & 0.878609 \\
\hline 2017 & 18.50104 & -21.814 & 58.81609 & 100.3201 & 71.38082 & 129.2593 & -7.98432 & -18.1956 & 2.020721 \\
\hline 2018 & 18.61911 & -21.9957 & 59.23391 & 101.8558 & 72.70443 & 131.0071 & -7.87947 & -19.3038 & 2.307763 \\
\hline 2019 & 18.73719 & -22.1752 & 59.64953 & 103.3915 & 74.02956 & 132.7534 & -7.75721 & -19.2299 & 3.012978 \\
\hline 2020 & 18.85526 & -22.3525 & 60.06301 & 104.9272 & 75.3562 & 134.4982 & -7.54641 & -18.9038 & 2.952696 \\
\hline 2021 & 18.97334 & -22.5277 & 60.47438 & 106.4629 & 76.6843 & 136.2416 & -7.61481 & -20.0339 & 3.766461 \\
\hline 2022 & 19.09141 & -22.7009 & 60.8837 & 107.9987 & 78.01384 & 137.9835 & -7.54753 & -19.6202 & 3.709595 \\
\hline 2023 & 19.20949 & -22.872 & 61.29099 & 109.5344 & 79.34479 & 139.724 & -7.35565 & -19.0295 & 4.097897 \\
\hline 2024 & 19.32756 & -23.0412 & 61.69632 & 111.0701 & 80.67712 & 141.4631 & -7.21228 & -20.3787 & 3.946288 \\
\hline 2025 & 19.44564 & -23.2084 & 62.09971 & 112.6058 & 82.0108 & 143.2009 & -7.09191 & -18.9601 & 4.640648 \\
\hline 2026 & 19.56371 & -23.3738 & 62.5012 & 114.1416 & 83.3458 & 144.9373 & -6.99333 & -19.3068 & 4.956842 \\
\hline 2027 & 19.68179 & -23.5373 & 62.90084 & 115.6773 & 84.68211 & 146.6724 & -6.91172 & -19.4663 & 5.404002 \\
\hline 2028 & 19.79986 & -23.6989 & 63.29865 & 117.213 & 86.01969 & 148.4063 & -6.97585 & -19.5051 & 5.262581 \\
\hline 2029 & 19.91794 & -23.8588 & 63.69468 & 118.7487 & 87.35852 & 150.1389 & -6.93265 & -19.1 & 4.788668 \\
\hline 2030 & 20.03601 & -24.0169 & 64.08895 & 120.2844 & 88.69858 & 151.8703 & -6.93248 & -18.7512 & 6.046848 \\
\hline 2031 & 20.15409 & -24.1733 & 64.4815 & 121.8202 & 90.04319 & 153.5971 & -6.74346 & -19.4279 & 5.276962 \\
\hline 2032 & 20.27216 & -24.3234 & 64.86775 & 123.3559 & 91.38893 & 155.3228 & -6.59377 & -19.382 & 5.660622 \\
\hline
\end{tabular}

${ }^{6}$ Random Walk Model with Drift : $\mathbf{K}_{\mathbf{t}}^{(\mathbf{f})}-\mathbf{K}_{\mathrm{t}-1}{ }^{(\mathrm{f})}=-0.34362$

${ }^{7}$ Random Walk Model with Drift + Dummy Variable1: $\mathbf{K}_{\mathbf{t}}^{(\mathbf{f})}-\mathbf{K}_{\mathbf{t}-1}{ }^{(\mathbf{f})}=-0.1166667-$ $13.16333 * \mathrm{PT}$

where $\mathrm{PT}=1$ when year $=2001$ and $\mathrm{PT}=0$ otherwise

${ }^{8}$ Vector Autoregressive (VAR) Model : $\mathbf{K}_{\mathbf{t}}{ }^{(\mathbf{f})}=1.059236473 * \mathbf{K}_{\mathbf{t}-1}{ }^{(\mathbf{f})}-0.343156097 *$ $\mathbf{K}_{\mathbf{t}-1}{ }^{(\mathbf{m})}-0.1980843972$ 
Finally, Table 4.6 shows forecasts of age-specific death rates per 100,000 at 5year intervals for the period 2010 - 2030 using our fitted VAR models for both male and female data. In Table 4.6, the forecasts for the period $2010-2030$ shows an upward trend in each age group which is quite expected as a result of the upward trend in the mortality forecasts shown in Figures 4.1(a) and 4.2(b). However, the lower limits of $95 \%$ confidence intervals for the forecasts of agespecific death rates per 100,000 showed a downward trend in agreement with those of LC for the same period $2010-2030$ suggesting the possibility of the actual death rates to show a downward trend. For example, for the forecasts of male death rates per 100,000, the lower bounds of the $95 \%$ confidence intervals for the years 2010, 2015, 2020, 2025, and 2030 were 65, 63, 63, 60, and 63 respectively in the 5-9 age group; 113,110, 110, 105, and 110 respectively in the 25 - 29 age group; and 634, 618, 620, 598, and 620 in the 55-59 age group. Corresponding values for the female death rates per 100,000 were 33, 26, 25, 24, and 25 in the $5-9$ age group; 63, 50 48, 48, and 48 in the $25-29$ age group; and $382,318,304,303$, and 306 in the $55-59$ age group.

Table 4.6: Forecasts* of age-specific death rates per 100,000 at five-year intervals, $2010-2030$

\begin{tabular}{|l|r|r|r|r|r|r|r|r|r|r|}
\hline $\begin{array}{l}\text { age } \\
\text { class }\end{array}$ & \multicolumn{9}{|c|}{ Males } & \multicolumn{5}{|c|}{ Females } \\
\hline & $\mathbf{2 0 1 0}$ & $\mathbf{2 0 1 5}$ & $\mathbf{2 0 2 0}$ & $\mathbf{2 0 2 5}$ & $\mathbf{2 0 3 0}$ & $\mathbf{2 0 1 0}$ & $\mathbf{2 0 1 5}$ & $\mathbf{2 0 2 0}$ & $\mathbf{2 0 2 5}$ & $\mathbf{2 0 3 0}$ \\
\hline $\mathbf{0 - 4}$ & 782 & 797 & 812 & 820 & 818 & 485 & 504 & 523 & 537 & 542 \\
\hline $\mathbf{5 - 9}$ & 90 & 92 & 95 & 96 & 96 & 54 & 57 & 61 & 63 & 64 \\
\hline $\mathbf{1 0 - 1 4}$ & 67 & 69 & 71 & 72 & 72 & 35 & 37 & 39 & 41 & 41 \\
\hline $\mathbf{1 5 - 1 9}$ & 118 & 121 & 124 & 126 & 125 & 63 & 67 & 71 & 73 & 74 \\
\hline $\mathbf{2 0 - 2 4}$ & 190 & 195 & 199 & 202 & 201 & 83 & 88 & 92 & 95 & 96 \\
\hline $\mathbf{2 5 - 2 9}$ & 213 & 218 & 223 & 226 & 225 & 92 & 97 & 102 & 106 & 107 \\
\hline $\mathbf{3 0 - 3 4}$ & 229 & 234 & 240 & 243 & 242 & 104 & 109 & 114 & 118 & 120 \\
\hline $\mathbf{3 5 - 3 9}$ & 322 & 330 & 337 & 341 & 340 & 132 & 139 & 146 & 150 & 152 \\
\hline $\mathbf{4 0 - 4 4}$ & 421 & 431 & 440 & 444 & 444 & 160 & 168 & 176 & 181 & 183 \\
\hline $\mathbf{4 5 - 4 9}$ & 630 & 643 & 656 & 662 & 661 & 237 & 247 & 258 & 266 & 269 \\
\hline $\mathbf{5 0 - 5 4}$ & 877 & 894 & 910 & 918 & 917 & 349 & 364 & 379 & 389 & 393 \\
\hline $\mathbf{5 5 - 5 9}$ & 1361 & 1385 & 1408 & 1420 & 1418 & 582 & 604 & 627 & 643 & 648 \\
\hline $\mathbf{6 0 - 6 4}$ & 1910 & 1940 & 1969 & 1985 & 1982 & 918 & 949 & 981 & 1004 & 1012 \\
\hline $\mathbf{6 5 - 6 9}$ & 3161 & 3205 & 3247 & 3269 & 3266 & 1791 & 1844 & 1897 & 1935 & 1948 \\
\hline $\mathbf{7 0 - 7 4}$ & 4893 & 4953 & 5009 & 5039 & 5034 & 3252 & 3333 & 3415 & 3473 & 3493 \\
\hline $\mathbf{7 5 +}$ & 12182 & 12286 & 12384 & 12435 & 12426 & 10254 & 10423 & 10592 & 10711 & 10753 \\
\hline
\end{tabular}

\footnotetext{
* The above forecasts were made using the VAR models; (Rounded off to the nearest integer)
} 


\section{Errors of Forecasts}

In Table 4.6 above, one can compute approximate 95\% confidence intervals for the forecasts of sex-specific death rates using LC approach as follows: Lower Bound $=(e s t.) e^{-b_{x}(m . e)}$; and Upper Bound $=(e s t.) e^{b_{x}(m . e)}$, where 'est.' is the forecast given in Table 4.6; $b_{\mathrm{x}}$ is the corresponding entry read from Table 4.1; and ' $m . e$ ' is the margin of error obtained from Table 4.4 or 4.5.

For example, approximate $95 \%$ confidence interval for the male death rate forecast in 2010 for the age group $0-4$ is computed as follows:

'est' $=782 ; b_{\mathrm{x}}=0.05897 ;$ 'm.e' $=4.169$. Thus, $95 \%$ confidence interval is: $\left(782 e^{-(0.05897(4.169)}, 782 e^{(.05897(4.169)}\right)=(611,999)$.

\section{Conclusions}

This study was mainly focused on modeling and forecasting mortality rates using Sri Lankan data and generating sex-specific life tables. Mortality was modeled using the Lee-Carter (1992) approach.

The number of registered deaths reveals historical episodes. There are peaks recorded in 1974, 1989, 1996 and 2005, due to two civil conflicts, the civil war and the tsunami incident, respectively. There are four peak points in 1974, 1989, 1996 and 2005 in the male graph, but only two peak points in the female graph in 1974 and 2005.

Out of several alternative time series models examined for modeling male and female mortality in Sri Lanka, a bivariate vector autoregressive (VAR) model performed better than the univariate models in this study, and produced relatively better forecasts.

From the 2006-2008 life table generated using estimated $\mathrm{k}_{\mathrm{t}}$ values as input, some important information was evident. The life expectancy at birth for males was 70.3 years, and 76.8 for females. The probability of a male aged 55 years surviving another 20 years was 0.71 , where as it was 0.85 for the females. Generally there was a downward trend in the mortality index for both sexes during the period 1950-2000 in agreement with similar studies elsewhere; but there was an upward trend from 2000-2008, and as a result the 30-year forecasts showed a slightly upward trend in both cases. However, the lower bounds of 95\% confidence intervals for the forecasts showed a downward trend indicating a possibility for the actual forecasts to follow a downward trend.

There were certain limitations too, in this study: Data on age-specific mortality rates were incomplete as the population size and the number of deaths for ages above 75 and separate data for age groups $0-1$ and $1-4$ were not available in 
Sri Lanka. The gaps in the data had to be estimated based on assumptions discussed earlier. Also, the time series models were fitted using only 59 data points available. Therefore, all data points were used for model fitting without keeping any as a test set.

This study will be further refined and extended in future work, with special emphasis on missing value estimation and outlier analysis.

\section{References}

1. Abeykoon A. T. P. L. (1996). "Demographic Implications of Health Care in Sri Lanka"Asia-Pacific Population Journal, 11(2), 47-58.

2. Borsch A. (2009). "Many Roads to Rome: Varieties of funded Pensions in Europe and Asia", Pensions: An international Journal, 14(3), 172.

3. Central Bank of Sri Lanka (2009). Annual Report.

4. De Silva I. W. (1994a). "Ahead of Target: Achievement of Replacement Level Fertility in Sri Lanka before the Year 2000", Asia-Pacific Population Journal, 9(4), 3-22.

5. De Silva I. W. (1994b). "How Serious is Ageing in Sri Lanka and What can be Done about it?",Asia-Pacific Population Journal, 9(1), 19-36.

6. De Silva I. W. (2005). "Family Transition in South Asia: Provision of Social Service and Social Protection", Asia-Pacific Population Journal, 1346.

7. De Silva I. W. (2007). "Beyond Twenty Million: Projecting the Population of Sri Lanka 2001-2081", Research Studies: Demographic Transition and Pension Series No. 6, Institute of Policy Studies, Colombo, Sri Lanka.

8. Department of Census and Statistics, Sri Lanka (2010). Statistical Abstract, www.statistics.gov.lk.

9. Dickey D. and Fuller W. A. (1979). "Distribution of the Estimates of Autoregressive Time Series with a Unit Root", Journal of the American Statistical Association 74 (June) 427-31.

10. Gamaniratne N. (2007). "Population Ageing, Policy Responses, and Options to Extend Retirement Coverage: Case Study of Sri Lanka" Research Studies: Demographic Transition and Pension Series No. 7, Institute of Policy Studies, Colombo, Sri Lanka. 
11. Good I. J (1969). "Some Applications of the Singular Decomposition of a Matrix", Technometrics, 11(4), 823-831.

DOI: $10.1080 / 00401706.1969 .10490741$

12. Johnson R. and Wichern D. (2002). Applied Multivariate Statistical Analysis Prentice Hall Press.

13. Lee R. D. and Carter L. R. (1992). "Modeling and Forecasting U.S. Mortality", Journal of the American Statistical Association, 87, 659-671.

14. Lee R.D. and Miller T. (2001). "Evaluating the Performance of the LeeCarter Method for Forecasting Mortality". Demography, 28, 537-549. DOI: $10.1353 /$ dem.2001.0036

15. Li N. and Lee R. (2005). "Coherent Mortality Forecasts for a Group of Populations: An Extension of the Lee-Carter Method”. Demography, 42, 575-594. DOI: 10.1353/dem.2005.0021.

16. Li N., Lee R., and Tuljapurkar S. (2004). "Using the Lee-Carter Method to Forecast Mortality for Populations with Limited Data", International Statistical Review, 72(1), 19-34. DOI: 10.1111/j.1751-5823.2004.tb00221.x.

17. Li J.S.H. and Chan W.S. (2007). "The Lee-Carter Model for Forecasting Mortality Revisited" North American Actuarial Journal, 11, 68-89.

DOI: 10.1080/10920277.2007.10597438.

18. Li J.S.H., Chan W.S., and Cheung S.H. (2011). "Structural Changes in the Lee-Carter Mortality Indexes: Detection and Implications". North American Actuarial Journal, 15, 13-31. DOI: 10.1080/10920277.2011.10597607.

19. Lütkepohl, H. (2005). New introduction to multiple time series analysis Cambridge University Press.

20. Ostbye T., Chan A., Malhotra R. and Kothalawala J. (2010). "Adult children caring for their elderly parents", Asian population Studies, 6(1), 8397. DOI: 10.1080/17441731003603504

21. United Nations. (2009). Department of Economic and Social Affairs, Population Division - World Population Ageing 2009. 
Modeling and Forecasting Mortality in Sri Lanka

\section{Appendix}

\section{Appendix 1}

Date: 04/03/13 Time: 15:01

Sample (adjusted): 19532008

Included observations: 56 after adjustments

Trend assumption: Linear deterministic trend

Series: KTF KTM

Lags interval (in first differences): 1 to 2

Unrestricted Cointegration Rank Test (Trace)

\begin{tabular}{lllll}
\hline \hline $\begin{array}{l}\text { Hypothesized } \\
\text { No. of CE(s) }\end{array}$ & Eigenvalue & $\begin{array}{l}\text { Trace } \\
\text { Statistic }\end{array}$ & $\begin{array}{l}0.05 \\
\text { Critical Value }\end{array}$ & Prob. $^{* *}$ \\
\hline \hline None & 0.174972 & 12.43147 & 15.49471 & 0.1374 \\
At most 1 & 0.029218 & 1.660559 & 3.841466 & 0.1975 \\
\hline \hline
\end{tabular}

Trace test indicates no cointegration at the 0.05 level

* denotes rejection of the hypothesis at the 0.05 level

${ }^{* *}$ MacKinnon-Haug-Michelis (1999) p-values

Unrestricted Cointegration Rank Test (Maximum Eigenvalue)

\begin{tabular}{lllll}
\hline \hline $\begin{array}{l}\text { Hypothesized } \\
\text { No. of CE(s) }\end{array}$ & Eigenvalue & $\begin{array}{l}\text { Max-Eigen } \\
\text { Statistic }\end{array}$ & $\begin{array}{l}0.05 \\
\text { Critical Value }\end{array}$ & \multirow{2}{*}{${\text { Prob. }{ }^{* *}}^{*}$} \\
\hline \hline None & 0.174972 & 10.77091 & 14.26460 & 0.1661 \\
At most 1 & 0.029218 & 1.660559 & 3.841466 & 0.1975 \\
\hline \hline
\end{tabular}

Max-eigenvalue test indicates no cointegration at the 0.05 level

* denotes rejection of the hypothesis at the 0.05 level

${ }^{* *}$ MacKinnon-Haug-Michelis (1999) p-values

\section{Appendix 2}

Vector Autoregression Estimates

Date: 04/02/13 Time: 13:16

Sample (adjusted): 19512008

Included observations: 58 after adjustments

Standard errors in ( ) \& t-statistics in [ ]

\begin{tabular}{lcc}
\hline \hline & KTF & KTM \\
\hline \hline \multirow{2}{*}{ KTF(-1) } & 1.059236 & 0.145376 \\
& $(0.10453)$ & $(0.07150)$ \\
& {$[10.1334]$} & {$[2.03311]$} \\
KTM(-1) & & \\
& -0.343156 & 0.498991 \\
& $(0.24454)$ & $(0.16728)$ \\
& {$[-1.40326]$} & {$[2.98296]$}
\end{tabular}


Wasana Aberathna, Lakshman Alles, W. N.Wickremasinghe and Isuru Hewapathirana

\begin{tabular}{lcc} 
C & -0.198084 & 0.055173 \\
& $(0.32601)$ & $(0.22301)$ \\
& {$[-0.60760]$} & {$[0.24740]$} \\
\hline \hline R-squared & 0.872755 & 0.672901 \\
Adj. R-squared & 0.868128 & 0.661007 \\
Sum sq. resids & 315.8837 & 147.8126 \\
S.E. equation & 2.396527 & 1.639360 \\
F-statistic & 188.6192 & 56.57251 \\
Log likelihood & -131.4514 & -109.4280 \\
Akaike AIC & 4.636256 & 3.876827 \\
Schwarz SC & 4.742831 & 3.983402 \\
Mean dependent & 0.067138 & 0.361897 \\
S.D. dependent & 6.599432 & 2.815652 \\
\hline \hline & & \\
Determinant resid covariance (dof adj.) & & 7.804374 \\
Determinant resid covariance & & 4.320223 \\
Log likelihood & & -207.0328 \\
Akaike information criterion & & 7.345958 \\
Schwarz criterion & & \\
\hline \hline
\end{tabular}

\section{Appendix 3}

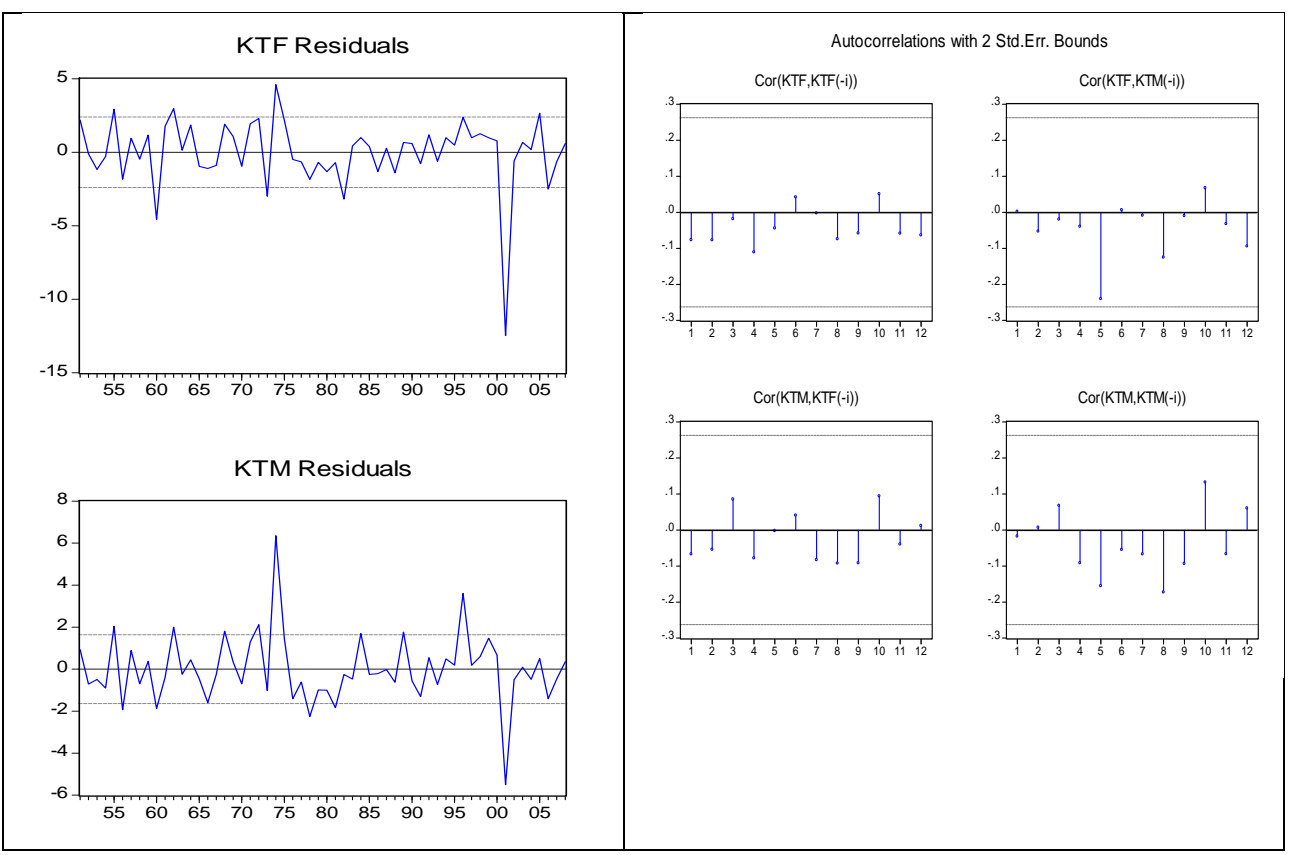


Modeling and Forecasting Mortality in Sri Lanka

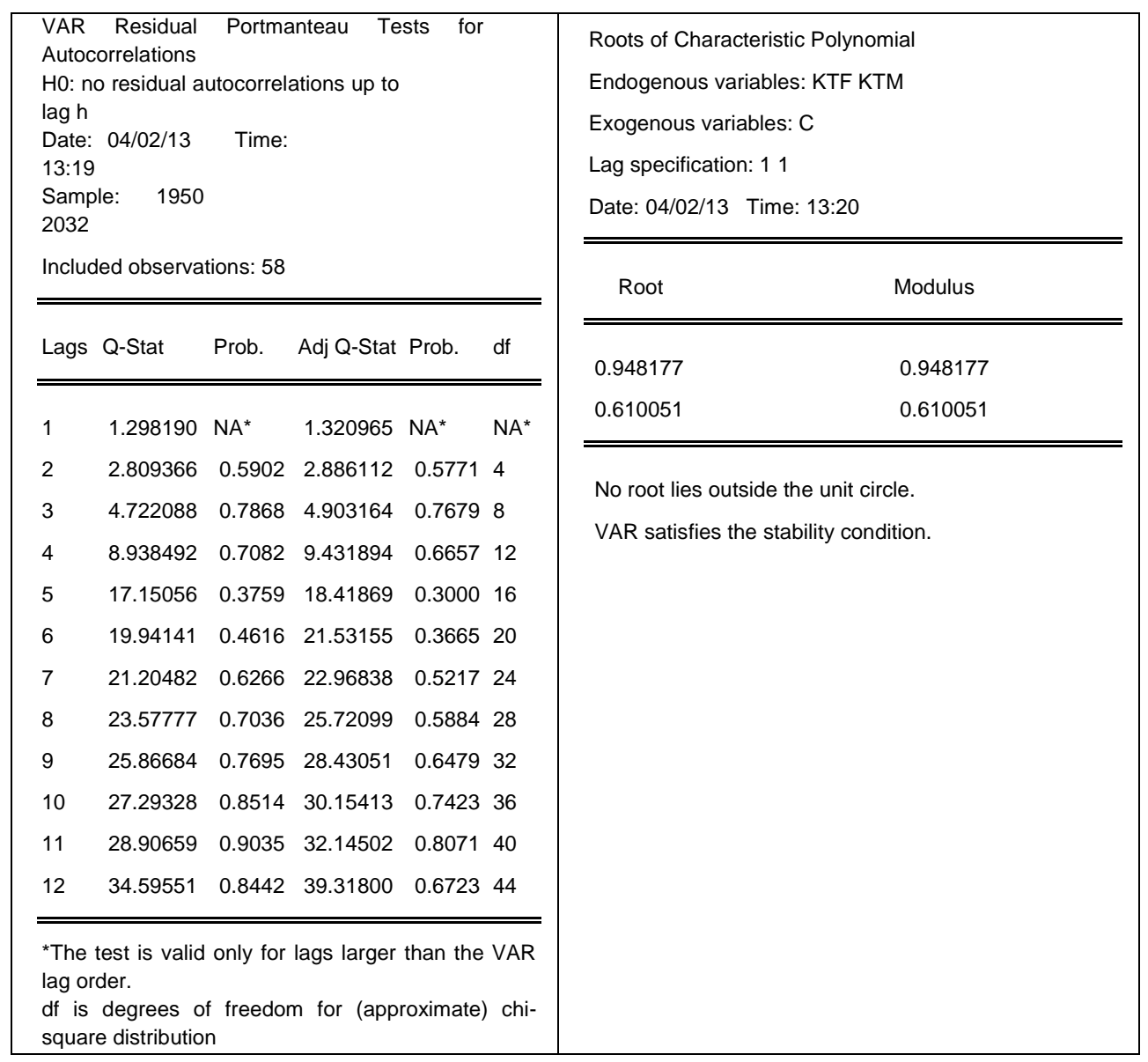


Wasana Aberathna, Lakshman Alles, W. N.Wickremasinghe and Isuru Hewapathirana 